\title{
Designing Data Warehouse in Finance Company Study at PT ABC
}

\author{
Putu Suta Adya Dharma Rahadi ${ }^{[1]}$, Putu Widiadnyana ${ }^{[2]}$, and Nengah Sweden ${ }^{[3]}$ \\ [1][2] Department of Electrical and Computer Engineering, Post Graduate Program, Udayana University \\ [3] Department of Electrical and Computer Engineering, Udayana University \\ E-Mail : suta.rahady@gmail.com
}

\begin{abstract}
Along with the development of technology and business needs that are more advanced, the more effective and efficient uses of Information Systems is an important thing for companies to continue competing in the era of globalization. Every company wants an appropriate Information System to run business activities smoothly. Using data warehouses can help PT $\mathrm{ABC}$ 's problems in accommodating large amounts of data with its OLTP system which can then be processed in determining future strategies through OLAP systems. So as to get the reports needed in maintaining the consistency and improve the performance of the company.
\end{abstract}

Keywords-Data Warehouse; Finance; Data Warehouse Design.

\section{INTRODUCTION}

Along with the development of technology and business needs that are more advanced, the more effective and efficient uses of Information Systems is an important thing for companies to continue competing in the era of globalization. Every company wants an appropriate Information System to run business activities smoothly. Therefore, changes due to these developments are indispensable to respond to existing business challenges.

In an Information System, of course there is a database that is used to store all data related to the business activities of a company. The stored data can be processed into certain information needed for the company. This stored data is the data needed and used for the day-to-day operations of the company concerned.

In addition to the usual database, there is also a data warehouse, which is a type of database used for the purposes of reporting and data analysis. Data warehousing technology $[1,2,3]$ in the data warehouse, all data stored in the company's database, even if the data is no longer exist in the database (historical). Data warehouse that works optimally is very important for companies so that the company can get complete, accurate, relevant, and punctual information based on data processing that exists in the data warehouse.
PT ABC Finance is a finance company or commonly known as leasing company which mostly engaged in car financing. Obviously, tABC Finance company does not want to be defeated by other competitor companies. The ABC Finance company has a lot of information stored in the company database. To be able to continue competitive in the market, PT ABC Finance needs a list of reports that are able to support the performance of PT ABC Finance.

This paper is written in the following format: Part II describes the concept of Data Warehouse, Tools in Data Warehouse. Part III describes the design of data warehouse at PT ABC Finance. Part IV is the conclusion of the study.

\section{LITERATURE REVIEW}

\section{A. Data Warehouse}

Data warehouse is a new paradigm in strategic decision making environment. Data warehouse is not a product but an environment where users can find strategic information. The data warehouse is a collection of logical data separate from the operational database and is a summary. The characteristics of the data warehouse are as follows [4].

- Subject Oriented

Data warehouse is a storage place based on the subject rather than the application. The subject is part of a company. Examples of subjects in the manufacturing company are sales, consumers, inventory, and so on. The picture below is the difference between the data warehouse and the operational database.
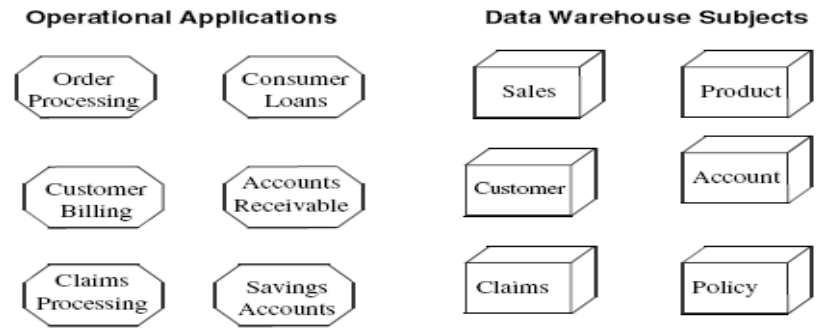

Fig. 1. Difference between data werehouse and operational database 
Tabel 1 Difference between operational database and data warehouse.

\begin{tabular}{|l|l|l|}
\hline & $\begin{array}{l}\text { Operational } \\
\text { Database }\end{array}$ & Data warehouse \\
\hline Data & $\begin{array}{l}\text { Now or up- } \\
\text { to-date }\end{array}$ & $\begin{array}{l}\text { Archive, history, } \\
\text { summary }\end{array}$ \\
\hline $\begin{array}{l}\text { Data } \\
\text { Structure }\end{array}$ & $\begin{array}{l}\text { Optimized } \\
\text { for } \\
\text { transactions, } \\
\text { normalization }\end{array}$ & $\begin{array}{l}\text { Optimized for } \\
\text { complex } \\
\text { queries, } \\
\text { Unnormalization }\end{array}$ \\
\hline $\begin{array}{l}\text { Frequency of } \\
\text { access }\end{array}$ & High & Medium-Low \\
\hline Access Type & $\begin{array}{l}\text { Read, update, } \\
\text { delete }\end{array}$ & Read \\
\hline Utilization & $\begin{array}{l}\text { Update } \\
\text { continuously }\end{array}$ & $\begin{array}{l}\text { Update } \\
\text { periodically }\end{array}$ \\
\hline Users & Many & Less \\
\hline
\end{tabular}

\section{- $\quad$ Integrated Data}

The data sources that exist in the data warehouse not only comes from the operational database (internal source) but also comes from data outside the system (external source). Data on different sources can be encoded in different ways. For example, gender data can be encoded as 0 and 1 in one place and " $m$ " and " $\mathrm{f}$ " elsewhere.

- Nonvolatile

Data in the operational database will be periodically or periodically transferred into the data warehouse in accordance with a predetermined schedule. For example per day, per week, per month, and so forth. Once entered into the data warehouse, the data is readonly. In Figure 2 below it can be seen that the OLTP database can be read, updated and deleted. But in the data warehouse database can only be read.

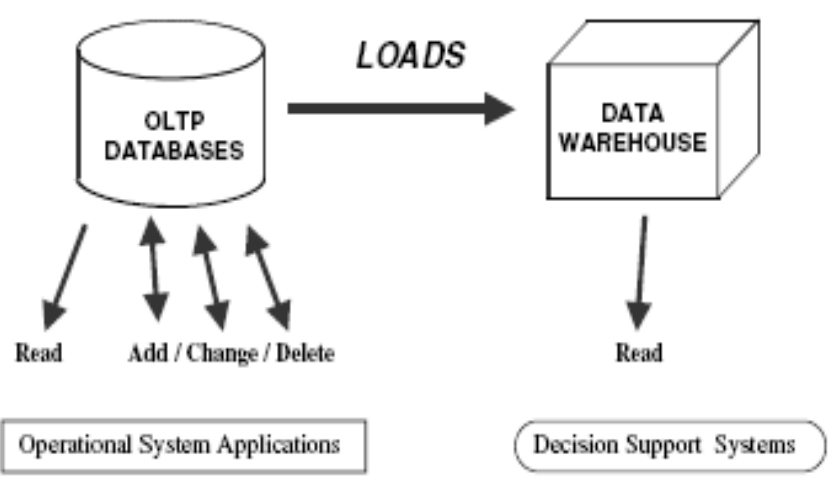

Fig. 2. Data Warehouse is nonvolatile

\section{- $\quad$ Time-Variant}

The operational system contains valuable data now while the data in the data warehouse contains data not only current data but also historical data to be used in analysis and decision making. Time is an important dimension that all data warehouses must support. Data for analysis from various sources contains various time values, eg daily, weekly, and monthly.

- Concise

Where necessary, operational data is collected into summaries.

- Granurality

In the operational system data is made in real-time so to obtain information directly performed the query process. In the data warehouse on analyzing should pay attention to level-of-detail eg per day, monthly summary, monthly summary.

- Not normalized

Data in a data warehouse is usually not normalized and very redundant. The basis of a data warehouse is a large data containing business information. The data in the data warehouse can come from many sources, eg from operational or transactional databases and external sources eg from the web, information service providers, from other companies, and so on. Data warehouse contains some important elements among others [5] :

1. Sumber Data sources used by data warehouses, transactional databases and external data sources.

2. Process ETL (Extraction, Transformation, Loading) from data source to database data warehouse.

3. Create a summary or summary of the data warehouse eg by using the aggregate function

4. Metadata

Metadata refers to data about data. Metadata describes the structure and some meanings of data, thereby supporting effective or ineffective use of data

5. Database data warehouse.

This database contains detailed data and summary data from the data contained in the data warehouse. Since data warehouses are not used in individual transaction processes, their database does not need to be organized for transaction access and for data retrieval, but is optimized for different access patterns in the analysis

6. Query Tools is with OLAP (Online Analytical Processing) and data mining. The tool for this query includes the end user interface in asking questions to the database, where the process is 
called On-line Analytical Processing (OLAP). This tool also consists of automated tools that find patterns in the data, which is often referred to as data mining. The data warehouse must have either of these two types or both.

7. User

Users who use the data warehouse.

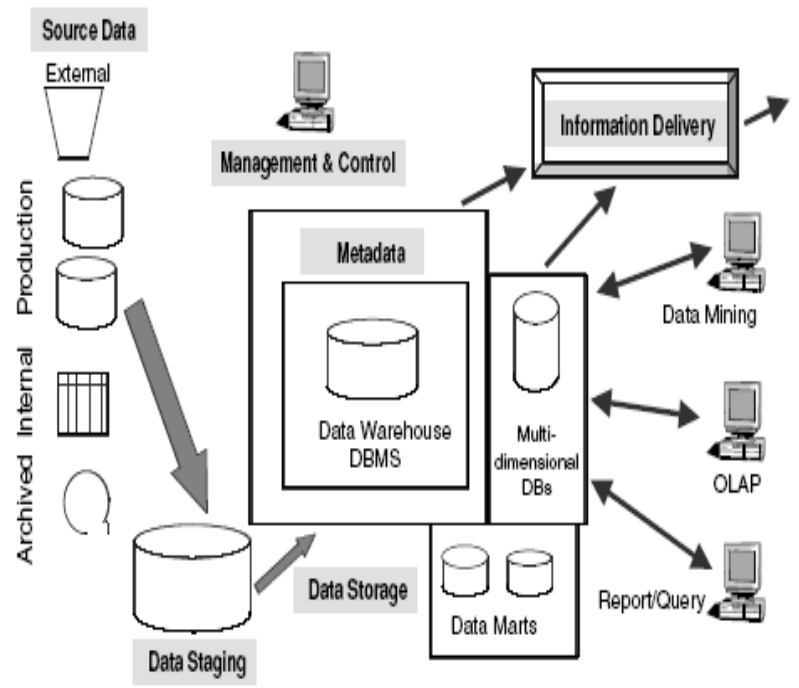

Fig. 3. Architecture Data Warehouse

\section{B. Conceptual Data Model (CDM)}

Conceptual Data Model is a database design based on data collection and analysis. Making CDM is a stage where we perform the process of identification and analysis of data needs and this is called data collection and analysis. To determine the needs of a database system, we must first identify the other parts of the information system that will interact with the database system. Data types are general and not specific.

\section{Physical Data Model (PDM)}

Physical Data Model is a physical database design. Data types are more specific and specific. The design of PDM is a physical representation of the database.

\section{OLTP (Online Transcation Processing)}

OLTP (Online Transaction Processing) is a process of online business transactions directly after the transaction occurs. For example, for example when buying goods in a store, the system directly reduces the stock inventory according to the amount of goods purchased and adds the amount of cash the store in accordance with the amount of money paid [6]

\section{E. OLAP (Online Transcation Processing)}

OLAP (Online Analytical Processing) is a dynamic blending, analysis, and consolidation of large multi dimensional data [7].

\section{RESULt ANALYSIS}

Fig 4 shows the result of the CDM's design for ABC Finance Company:

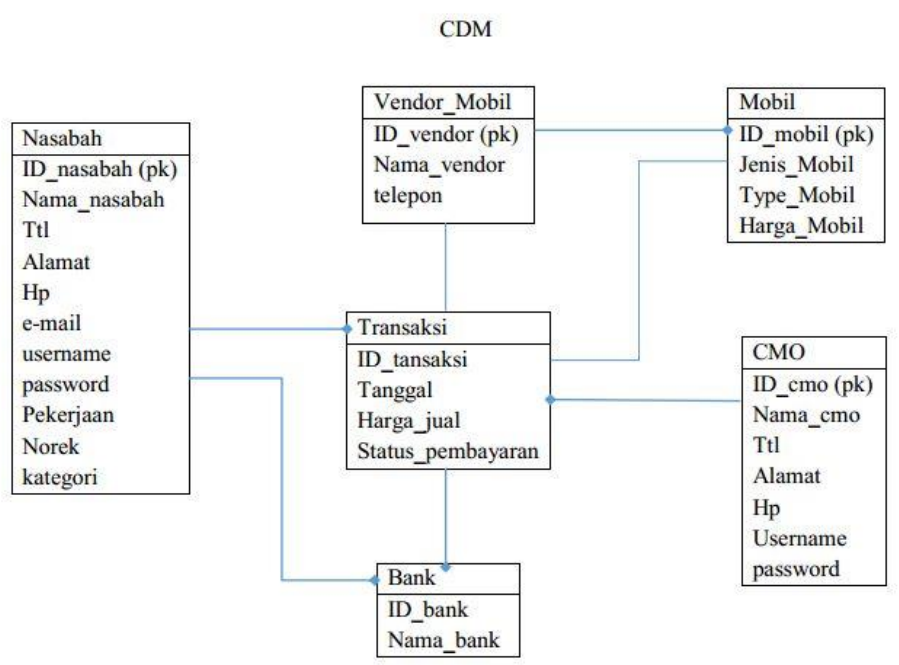

Fig. 4. CDM PT Finance ABC

Fig 5 shows the result of the PDM's design for ABC Finance Company:

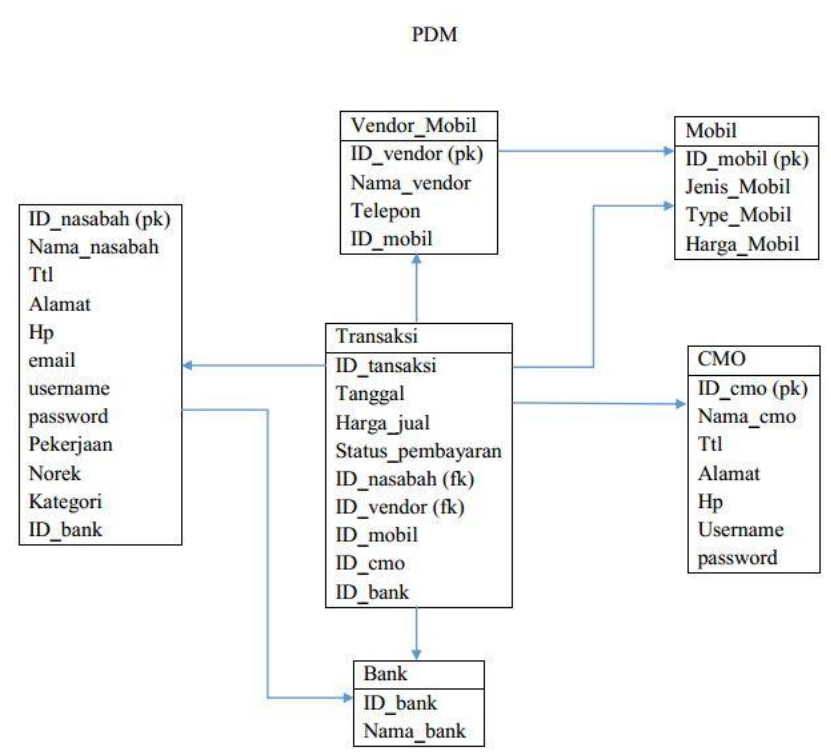

Fig. 5. PDM PT Finance ABC 
After the CDM and PDM are completed then the next step is the creation of the client-server model. In the client-server model generally, the client will request directly to the server. The client is responsible for handling user input, while the server is responsible for handling database operation requests. Through clients, customers can make transactions easily and customers get faster responses.

These processes involve examination of authorization, integrity assurance, data dictionary maintenance and query processing and updating process. It also provides control over concurrency and recovery. Because in its implementation, ABC Finance company covers a fairly large area of the city, the architecture chosen is using the Three Tier.

Next is to create database design for OLTP (Online Transaction Processing) and OLAP (Online Analytical Processing). OLTP is any handling action in the daily transactions' process, for example in the case of ABC Finance, OLTP handles all purchasing process conducted by the company's customer. The assumption, every day the company always receives an average of 10 customer transactions, so you can imagine if the transactions data pounded for months, even year.

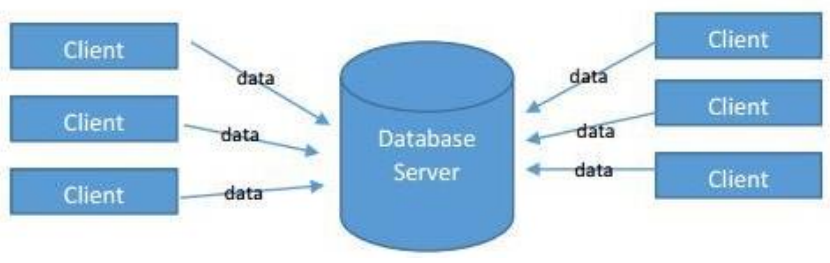

Fig. 6. OLTP PT Finance ABC

OLAP is used for decision making, e.g. ABC Finance company wants to see monthly transactions, for 6 months to take any car decisions that are less interesting or even not sold in the market. The steps in fulfilling client requests are metadata preparation, create relational databases, load staging databases, load relational database data marts, load extension and attribute tables, deploy and cube process, backup and discard databases.

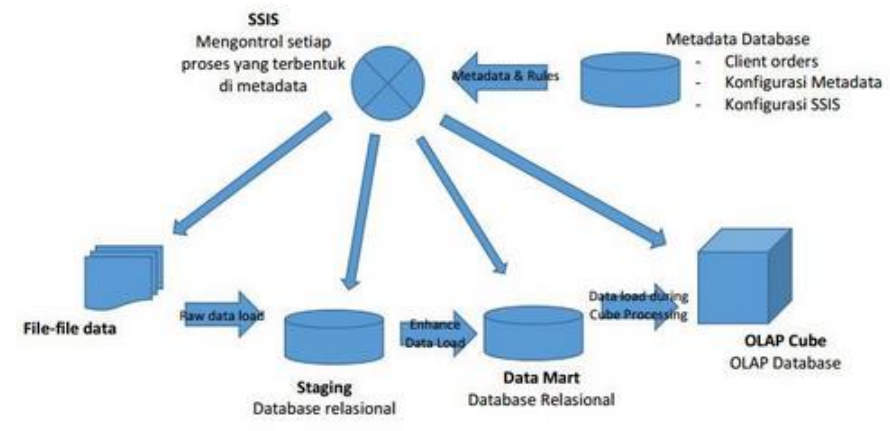

Fig. 7. OLAP PT Finance ABC

\section{CONCLUSION}

The existence of a data warehouse in a company and client server database enables large database access. Through the Three Tier method, the clients of each branch can connect to the system to facilitate the data collection into the server. This system can help the problems of PT Finance ABC in accommodating the data in very large amounts with its OLTP system which can then be processed in determining the future strategy through OLAP system, also to get the necessary reports in maintaining the consistency and improving the company's performance.

\section{REFERENCES}

[1] W.H. Inmon, Building the Data Warehouse, John Wiley \& Sons, 2nd edition, 1996

[2] R. Kimball, The Data Warehouse Toolkit - Practical Techniques for Building Dimensional Data Warehouses, John Wiley Professio, 1996.

[3] R. Kimball, L. Reeves, M. Ross and W. Thornthwaite, The Data Warehouse Lifecycle Toolkit, Willey Computer Publishings, 1998.

[4] Ponniah, Paulraj. 2001. Data Warehouse Fundamentals: a Comprehensive Guide for IT Professional. New York : John Wiley \& Sons.

[5] Mallach, Efrem G, 2000. Decision Support and Data Warehouse Systems. Singapore: Irwin McGraw Hill.

[6] Rainer Jr., R. Kelly, and Casey G Cegielski. Introduction to Information Systems. Singapore: John Wiley \& Sons, 2013..

[7] Connolly, Thomas M, and Carolyn E Begg. Database Systems : A Practical Approach to Design, Implementation, and Management. Boston: Pearson Education, 2010. 